Browse Conference Publications > Personal, Indoor and Mobile R ...

\title{
Interference cancellation with combined pre-distortion filtering and transmit diversity
}

园 Full Text

Sign-In or Purchase
Need Full-Text?

Request a free trial to IEEE Xplore for your organization.

2

Marques da Silva, M. ; Inst. for Telecommun., Lisboa, Portugal ; Correia, A.M.C.

Author(s)

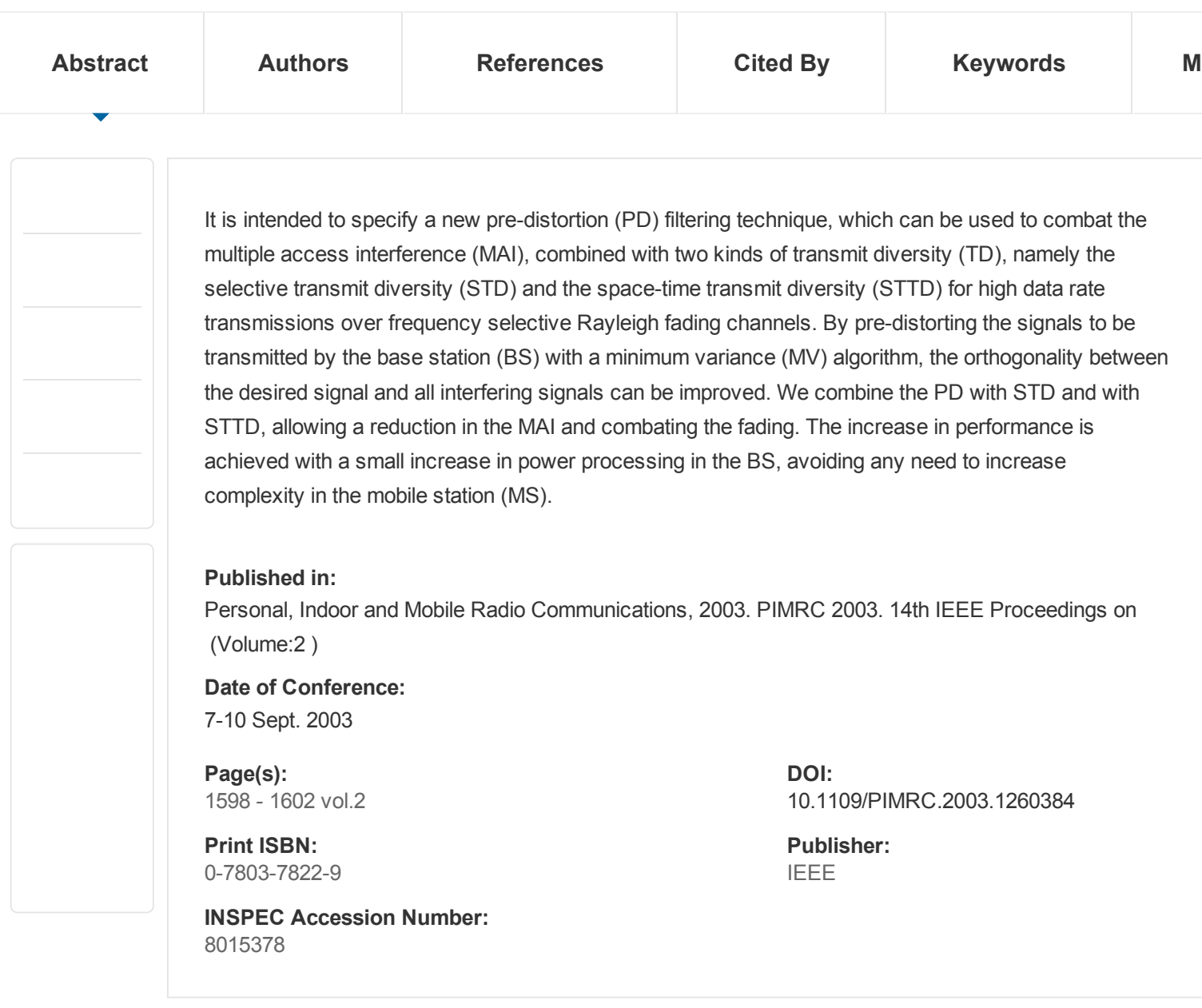

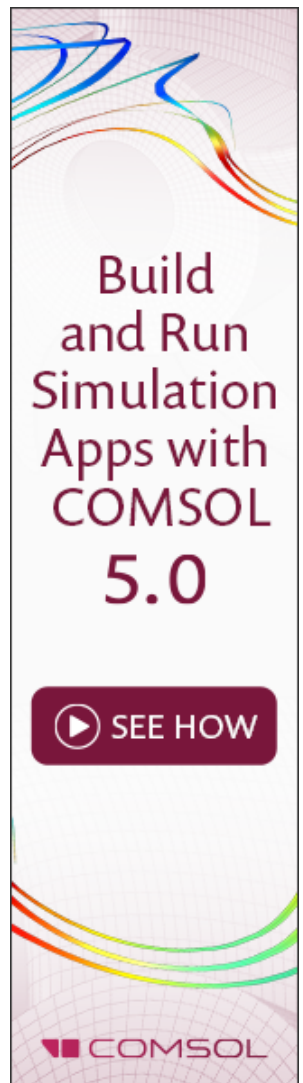

Personal Sign In | Create Account

$\begin{array}{lll}\text { IEEE Account } & \text { Purchase Details } & \text { Profile Information } \\ \text { "Change Username/Password } & \text { »Payment Options } & \text { "Communications Preferences } \\ \text { " Update Address } & \text { "Order History } & \text { "Profession and Education } \\ & \text { »Access Purchased Documents } & \text { "Technical Interests }\end{array}$

Need Help?

»US \& Canada: +18006784333

» Worldwide: +1 7329810060

»Contact \& Support 